\title{
Otorhinolaryngological adverse effects of urological drugs
}

\author{
Nathalia de Paula Doyle Maia ${ }^{1}$, Karen de Carvalho Lopes ${ }^{2}$, Fernando Freitas Ganança ${ }^{2}$ \\ ${ }^{1}$ Programa de Pós-Graduação em Medicina, Otorrinolaringologia da Universidade Federal de São Paulo \\ - Escola Paulista de Medicina - UNIFESP, São Paulo, SP, Brasil; ${ }^{2}$ Departamento de Otorrinolaringologia \\ e Cirurgia de Cabeça e Pescoço da Universidade Federal de São Paulo - Escola Paulista de Medicina - \\ UNIFESP, São Paulo, SP, Brasil
}

\section{ABSTRACT}

Purpose: To describe the otorhinolaryngological adverse effects of the main drugs used in urological practice.

Materials and Methods: A review of the scientific literature was performed using a combination of specific descriptors (side effect, adverse effect, scopolamine, sildenafil, tadalafil, vardenafil, oxybutynin, tolterodine, spironolactone, furosemide, hydrochlorothiazide, doxazosin, alfuzosin, terazosin, prazosin, tamsulosin, desmopressin) contained in publications until April 2020. Manuscripts written in English, Portuguese, and Spanish were manually selected from the title and abstract. The main drugs used in Urology were divided into five groups to describe their possible adverse effects: alpha-blockers, anticholinergics, diuretics, hormones, and phosphodiesterase inhibitors.

Results: The main drugs used in Urology may cause several otorhinolaryngological adverse effects. Dizziness was most common, but dry mouth, rhinitis, nasal congestion, epistaxis, hearing loss, tinnitus, and rhinorrhea were also reported and varies among drug classes.

Conclusions: Most of the drugs used in urological practice have otorhinolaryngological adverse effects. Dizziness was most common, but dry mouth, rhinitis, nasal congestion, epistaxis, hearing loss, tinnitus, and rhinorrhea were also reported. Therefore, doctors must be aware of these adverse effects to improve adherence to the treatment and to minimize damage to the health of patients.

\section{ARTICLE INFO}

Fernando Gananca

http://orcid.org/0000-0002-8703-9818

\section{Keywords:}

Cholinergic Antagonists;

Adrenergic alpha-1 Receptor

Antagonists; Deamino Arginine

Vasopressin

Int Braz J Urol. 2021; 47: 747-52

Submitted for publication:

June 24, 2020

Accepted after revision:

July 15, 2020

Published as Ahead of Print:

August 25, 2020

\section{INTRODUCTION}

The treatment of urological disorders such as urinary tract infection and erectile dysfunction has spread to several medical specialties besides Urology, including among others, general practitioners. It is important to emphasize that drugs, especially when administered orally, may have effects on other parts of the human body besides the genitourinary tract (1). In addition to reducing the adherence of patients to treatment, the adverse effects may generate serious risks to the health of patients and hinder the management of urological diseases. Researchers are always looking for new drugs with better efficacy, safety, and tolerability (2). However, doctors must know the adverse effects of drugs to contraindicate their use or at least detect them promptly aiming minimizing the damage to the patient's health. This study aims to describe the otorhinolaryngological adverse effects of the main drugs used in urological practice. 


\section{MATERIALS AND METHODS}

A review of the scientific literature was performed using a combination of specific descriptors (side effect, adverse effect, scopolamine, sildenafil, tadalafil, vardenafil, oxybutynin, tolterodine, spironolactone, furosemide, hydrochlorothiazide, doxazosin, alfuzosin, terazosin, prazosin, tamsulosin, desmopressin) contained in publications until April 2020. Manuscripts written in English, Portuguese, and Spanish were manually selected from the title and abstract. Studies that did not provide information sufficient for analysis were excluded. Additional bibliographical research was carried out to provide specific information on the drugs used in urological practice. The necessary information and data were extracted from the selected studies. The main drugs used in urology were divided into five groups: alpha-blockers, anticholinergics, diuretics, hormones, and phosphodiesterase inhibitors.

\section{RESULTS}

\section{Alpha-blockers}

Alpha-1 adrenergic receptor blockers $(\alpha$-blockers) are widely used in the management of patients with benign prostatic hyperplasia but were originally developed for the treatment of systemic arterial hypertension (3). Examples of drugs in this group are doxazosin, terazosin, prazosin, alfuzosin, and tamsulosin. The blocking of alpha-1 adrenergic receptors in the genitourinary tract promotes relaxation of the smooth muscle of the prostate, urethra, and neck of the bladder with a consequent decrease in pressure in the prostate urethra and facilitating urinary flow (3).

Because of the distribution of alpha-1 adrenergic receptors in various organs and systems, the adverse effects that may occur during treatment with these drugs involve, but are not limited to, postural dizziness, lethargy, fatigue, fluid retention, rhinitis, sexual dysfunction, asthenia, syncope, headache, visual clouding, nasal congestion and xerostomia (3-6). Third-generation alpha-1 adrenergic blockers (alfuzosin, tamsulosin) are considered "uro-selective" and are rarely associated with adverse cardiovascular or central ner- vous system effects and can be safely prescribed in contrast to their predecessors (doxazosin, terazosin, prazosin) $(7,8)$. Dizziness and rhinitis have been described as adverse effects of tamsulosin (9).

\section{Anticholinergics}

Scopolamine is the main non-selective antagonist drug of acetylcholine muscarinic receptors used in Urology $(10,11)$. In the genitourinary tract, it promotes an increase in bladder capacity, decreasing the frequency of contractions of the detrusor muscle, and delaying the initial desire to urinate (12). In otorhinolaryngology, this drug can be used transdermal in some patients to prevent and treat motion sickness (10). It is also useful in suppressing pendular nystagmus and downbeat nystagmus since the drug acts on the muscarinic receptors present in the medial vestibular nucleus, a structure responsible for maintaining the eyes in an eccentric position (13).

The main adverse effects of anticholinergics, especially scopolamine, are increased intraocular pressure, xerostomia, dizziness, visual clouding, and decreased concentration, micturition dysfunction, tachycardia, and sleepiness $(14,15)$. Transdermal administration of scopolamine was developed to reduce serious adverse effects and maintain the action of the drug over an extended time (approximately 72 hours), with xerostomia being the main adverse effect when administered by this route (11). After transdermal administration, adverse effects on the central nervous system (disorientation, memory disorders, dizziness, restlessness, hallucinations, confusion, and insomnia) have been reported with low frequency (16). No significant influence on the sense of smell was identified after the systemic administration of scopolamine hydrobromide (17).

Oxybutynin and tolterodine are powerful antagonists of muscle receptors (18) and have been used in the treatment of overactive bladder for over 40 years $(19,20)$. The adverse effects of these drugs differ little from those associated with scopolamine; xerostomia, visual clouding, constipation, erythema, fatigue, sweating, dizziness, cognitive changes, sleepiness, and urinary retention have been reported in the literature (18, 
19, 21, 22). Epistaxis, characterized by the nasal-mucosa dryness as the main factor, was reported as an adverse effect of oxybutynin but was seen in one patient only (23). Facial flushing is another frequent adverse effect due to vasodilation that can play a role in triggering epistaxis (23). In comparison to oxybutynin that acts mainly on the subtypes M1 and M3 of muscle receptors and is more present in the parotid than in the bladder, tolterodine acts on subtypes M2 and M3 muscle receptors and has fewer adverse effects because it reaches the bladder more than any other areas of the body (20). The study by Paquette et al. evaluated the cognitive performance of patients who used anticholinergic drugs; dizziness was the most frequently reported adverse effect that was observed in 3\% of people who used oxybutynin, 1.8\% who used tolterodine, and 1.6\% on placebo (24).

\section{Diuretics}

Diuretics are widely used for the treatment of systemic arterial hypertension and edematous states. There are several classes of diuretics drugs that act through various mechanisms of action (25). There are three main classes of diuretics drugs routinely used in clinical practice that have adverse effects - loop diuretics such as furosemide, potassium-sparing diuretics such as spironolactone, and thiazide such as hydrochlorothiazide.

Furosemide is the main representative of loop diuretics (26). Common adverse effects of this class of drugs include headache, gastrointestinal disorders, hypernatremia, hypokalemia, and dehydration (27). Its otorhinolaryngological effects include hearing loss, tinnitus, and dizziness/vertigo (28). Ototoxicity is a relevant adverse effect that can be transient or permanent (29). Several investigations to elucidate the ototoxicity mechanisms of furosemide have been performed, but they are still unknown (29). Methods to avoid ototoxicity include slow and continuous infusion instead of bolus injection, use of fractionated oral doses, and even the quantification of blood levels to avoid the serum concentration of furosemide above $50 \mu \mathrm{g} / \mathrm{mL}$ (29).

Spironolactone is a diuretic aldosterone antagonist and potassium-sparing diuretic (26).
Aqueous rhinorrhea adverse effect was observed during an otorhinolaryngological physical examination that coincided with the use of spironolactone (30). The clear aspect of nasal fluid, chemo-cytological analysis, and glucose levels ruled out the differential diagnosis of cerebrospinal fluid. Moreover, rhinorrhea ceased after the suspension of the drug and recurred after repeated introduction (30). One possible explanation is that spironolactone may decrease the vascular response to norepinephrine, with the consequent nasal vasodilator effect triggering aqueous rhinorrhea (30).

Hydrochlorothiazide is the most widely used thiazide-type diuretic (31). Common adverse effects of this class of drugs include nausea, dizziness, headache, polyuria, dehydration, hyponatremia, hypokalemia, and hypomagnesemia (32).

\section{Hormones}

Desmopressin (DDAVP) is an analog of vasopressin and is a potent agonist of the vasopressin-2 receptor (VR2) used in the management of diabetes insipidus, night enuresis, and hematological disorders (33). DDAVP increases water reabsorption by acting on the renal tubules, with the consequent increase in urinary osmolality and a decrease in urinary volume (34).

Vasopressin type 2 receptors are also found in other sites besides the kidney such as the inner ear and vascular endothelium (35). The use of desmopressin may be associated with a worsening of endolymphatic hydrops in the inner ear through the presence of VR2 in the endolymphatic sac (36-39). These receptors are also associated with increased levels of clotting factor VIII, von Willebrand factor, and tissue plasminogen activator in endothelial cells (35). A systematic review suggested the use of DDAVP in otorhinolaryngological surgical procedures as a prophylactic agent in the perioperative period and as an intervention agent in postoperative bleeding (40).

Desmopressin has few adverse effects with the most common being facial flushing. Other adverse effects include headache, decreased blood pressure, tachycardia, fatigue, and dizziness $(33,41,42)$. 


\section{Phosphodiesterase inhibitors}

Initially developed for the control of systemic arterial hypertension and angina pectoris, phosphodiesterase-5 inhibitors (iPDE5) are now widely used for the management of penile erection when this action has been observed as an adverse effect of a drug (43). Sildenafil, tadalafil, and vardenafil are the main representatives of iPDE5. The most frequently reported adverse effects associated with the use of these drugs are headache, facial flushing, dyspepsia, nasal congestion, rhinitis, visual disorders, and myalgia (44). Otorhinolaryngological adverse effects associated with the use of iPDE5 include sudden hearing loss, usually unilateral, occurring in the first three days after using the drug and frequen- tly associated with tinnitus, dizziness, or vertigo (44), epistaxis has also been observed with some patients (6).

The main otorhinolaryngological adverse effects of drugs most commonly used in urological practice are listed in Table-1.

\section{CONCLUSIONS}

Most of the drugs used in urological practice have otorhinolaryngological adverse effects. Dizziness was most common, but dry mouth, rhinitis, nasal congestion, epistaxis, hearing loss, tinnitus, and rhinorrhea were also reported. Therefore, doctors must be aware of these adverse effects and identify them early to minimize pos-

Table 1 - The main otorhinolaryngological adverse effects of drugs most commonly used in urological practice.

\begin{tabular}{lcc}
\hline Class & Drug & Adverse effects \\
\hline Alpha-blocker & Doxazosin & Rhinitis, nasal congestion, xerostomia \\
& Terazosin & Rhinitis, nasal congestion, xerostomia \\
& Prazosin & Rhinitis, nasal congestion, xerostomia \\
Anticholinergic & Alfuzosin & Rhinitis, nasal congestion, xerostomia \\
& Tamsulosin & Dizziness, rhinitis \\
Siuretic & Scopolamine & Xerostomia, dizziness, suppression \\
Phosphodiesterase inhibitor & Oxybutynin & Xerostomia, dizziness, epistaxis \\
normone & Tolterodine & Xerostomia, dizziness \\
& Furosemide & Hearing loss, tinnitus, dizziness/vertigo \\
& Spironolactone & Rhinorrhea \\
Hydrochlorothiazide & Dizziness
\end{tabular}


sible damage to the health of patients and poor adherence to treatments, or even contraindicate the use of some drugs.

\section{CONFLICT OF INTEREST}

None declared.

\section{REFERENCES}

1. Farokhzad OC, Dimitrakov JD, Karp JM, Khademhosseini A, Freeman MR, Langer R. Drug delivery systems in urology-getting "smarter". Urology. 2006; 68:463-9.

2. Eardley I, Whelan P, Kirby R, Schaeffer A. Drug treatment in urology: John Wiley \& Sons; 2008; p. X.

3. Djavan B, Marberger M. A meta-analysis on the efficacy and tolerability of alpha1-adrenoceptor antagonists in patients with lower urinary tract symptoms suggestive of benign prostatic obstruction. Eur Urol. 1999; 36:1-13.

4. Taylor SH. Pharmacotherapeutic stature of doxazosin and its role in coronary risk reduction. Am Heart J. 1988; 116(6 Pt 2):1735-47.

5. Roehrborn CG, Schwinn DA. Alpha1-adrenergic receptors and their inhibitors in lower urinary tract symptoms and benign prostatic hyperplasia. J Urol. 2004; 171:1029-35.

6. Bateman ND, Woolford TJ. The rhinological side-effects of systemic drugs. Clin Otolaryngol Allied Sci. 2003; 28:381-5.

7. Agrawal MS, Yadav A, Yadav H, Singh AK, Lavania P, Jaiman R. A prospective randomized study comparing alfuzosin and tamsulosin in the management of patients suffering from acute urinary retention caused by benign prostatic hyperplasia. Indian J Urol. 2009; 25:474-8.

8. Höfner K, Jonas U. Alfuzosin: a clinically uroselective alpha1blocker. World J Urol. 2002; 19:405-12.

9. Lyseng-Williamson KA, Jarvis B, Wagstaff AJ. Tamsulosin: an update of its role in the management of lower urinary tract symptoms. Drugs. 2002; 62:135-67.

10. Powell-Dunford N, Bushby A. Management of Sea Sickness in Susceptible Flight Crews. Mil Med. 2017; 182:e1846-50.

11. Gordon CR, Gonen A, Nachum Z, Doweck I, Spitzer O, Shupak $A$. The effects of dimenhydrinate, cinnarizine and transdermal scopolamine on performance. J Psychopharmacol. 2001; 15:167-72.

12. Wiener LB, Baum NH, Suarez GM. New method for management of detrusor instability: transdermal scopolamine. Urology. 1986; 28:208-10.
13. Kim JI, Averbuch-Heller L, Leigh RJ. Evaluation of transdermal scopolamine as treatment for acquired nystagmus. J Neuroophthalmol. 2001; 21:188-92.

14. Huppert D, Strupp M, Mückter H, Brandt T. Which medication do I need to manage dizzy patients? Acta Otolaryngol. 2011; 131:228-41.

15. Averbuch-Heller L. Acquired Nystagmus. Curr Treat Options Neurol. 1999; 1:68-73.

16. Wilkinson JA. Side effects of transdermal scopolamine. J Emerg Med. 1987; 5:389-92.

17. Doty RL, Bagla R, Misra R, Mueller E, Kerr KL. No influence of scopolamine hydrobromide on odor detection performance of rats. Chem Senses. 2003; 28:761-5.

18. Cohn JA, Brown ET, Reynolds WS, Kaufman MR, Milam DF, Dmochowski RR. An update on the use of transdermal oxybutynin in the management of overactive bladder disorder. Ther Adv Urol. 2016; 8:83-90.

19. Yamada S, Ito Y, Nishijima S, Kadekawa K, Sugaya K. Basic and clinical aspects of antimuscarinic agents used to treat overactive bladder. Pharmacol Ther. 2018; 189:130-48.

20. Aziminekoo E, Ghanbari Z, Hashemi S, Nemati M, Haghollahi F, Shokuhi N. Oxybutynin and tolterodine in a trial for treatment of overactive bladder in Iranian women. J Family Reprod Health. 2014; 8:73-6.

21. Hesch K. Agents for treatment of overactive bladder: a therapeutic class review. Proc (Bayl Univ Med Cent). 2007; 20:307-14.

22. Molina A, Pérez A, Pisón J. Epistaxis as a side effect of treatment of bladder hyperactivity with oxybutynin. An Sist Sanit Navar. 2013; 36:135-6.

23. Batista JE, Caffaratti J, Garat JM. Epistaxis as a side effect of oxybutynin in children: report of two cases. Neurourol Urodyn. 1994; 13:85-6.

24. Paquette A, Gou P, Tannenbaum C. Systematic review and meta-analysis: do clinical trials testing antimuscarinic agents for overactive bladder adequately measure central nervous system adverse events? J Am Geriatr Soc. 2011; 59:1332-9.

25. Greenberg A. Use of Diuretics in Chronic Kidney Disease Patients. Chronic Renal Disease: Elsevier; 2020. p. 1053-70.

26. Carone L, Oxberry SG, Twycross R, Charlesworth S, Mihalyo M, Wilcock A. Spironolactone. J Pain Symptom Manage. 2017; 53:288-92.

27. [No Authors]. Loop Diuretics. LiverTox: Clinical and Research Information on Drug-Induced Liver Injury. National Institutes of Health. 2012. [Internet]. Available at. <https://www.ncbi. nlm.nih.gov/books/NBK548619/>

28. Lee CA, Mistry D, Uppal S, Coatesworth AP. Otologic side effects of drugs. J Laryngol Otol. 2005; 119:267-71. 
29. Rybak LP. Pathophysiology of furosemide ototoxicity. J Otolaryngol. 1982; 11:127-33.

30. Ayerbe García-Monzón L, Herrero Hernández S, González López E, Alcaraz Borrajo M. Rinorrea secundaria a espironolactona [Rhinorrhea as side-effect of spironolactone]. Aten Primaria. 2004; 33:164.

31. Sica DA, Carter B, Cushman W, Hamm L. Thiazide and loop diuretics. J Clin Hypertens (Greenwich). 2011; 13:639-43.

32. [No Authors]. Thiazide Diuretics. LiverTox: Clinical and Research Information on Drug-Induced Liver Injury. National Institutes of Health. 2012. [Internet]. Available at. <https:// www.ncbi.nlm.nih.gov/books/NBK548680/>

33. Lethagen S. Desmopressin (DDAVP) and hemostasis. Ann Hematol. 1994; 69:173-80.

34. Boone M, Deen PM. Physiology and pathophysiology of the vasopressin-regulated renal water reabsorption. Pflugers Arch. 2008; 456:1005-24.

35. Juul KV, Bichet DG, Nielsen S, Nørgaard JP. The physiological and pathophysiological functions of renal and extrarenal vasopressin V2 receptors. Am J Physiol Renal Physiol. 2014; 306:F931-40.

36. Egami N, Kakigi A, Sakamoto T, Takeda T, Hyodo M, Yamasoba T. Morphological and functional changes in a new animal model of Ménière's disease. Lab Invest. 2013; 93:1001-11.

37. Ciuman RR. Inner ear symptoms and disease: pathophysiological understanding and therapeutic options. Med Sci Monit. 2013; 19:1195-210.

38. Semaan MT, Megerian CA. Contemporary perspectives on the pathophysiology of Meniere's disease: implications for treatment. Curr Opin Otolaryngol Head Neck Surg. 2010; 18:392-8.
39. Kim M, Kim KS. Vestibular Function Change in a VasopressinInduced Hydrops Model. Otol Neurotol. 2017; 38:e495-e500.

40. Barinsky GL, Buziashvili D, Svider PF, Carron MA, Folbe AJ, Hsueh WD, et al. Perioperative Desmopressin for Patients Undergoing Otolaryngologic Procedures: A Systematic Review. Otolaryngol Head Neck Surg. 2019; 161:36-45.

41. Kapila V, Kapila AK, Tailly T, Rappe B, Juul KV, Everaert K. The analgesic action of desmopressin in renal colic. Acta Clin Belg. 2017; 72:179-85.

42. Jacobs GE, Hulskotte EG, van Gerven JM, Zuurman L, de Kam ML, Elassaiss-Schaap J, et al. Desmopressin as a pharmacological tool in vasopressinergic hypothalamuspituitary-adrenal axis modulation: neuroendocrine, cardiovascular and coagulatory effects. J Psychopharmacol. 2011; 25:353-60.

43. Dhaliwal A, Gupta M. PDE5 Inhibitor. StatPearls 2020 [Internet]. Available at. <https://www.ncbi.nlm.nih.gov/ books/NBK549843/>

44. Smith WB 2nd, McCaslin IR, Gokce A, Mandava SH, Trost L, Hellstrom WJ. PDE5 inhibitors: considerations for preference and long-term adherence. Int J Clin Pract. 2013; 67:768-80.

Correspondence address: Fernando Freitas Ganança, MD, PhD Disciplina de Otologia e Otoneurologia, Universidade Federal de São Paulo - Unifesp, Escola Paulista de Medicina (EPM), São Paulo, SP, Brasil E-mail: ffgananca@gmail.com 